CIRJE-F-1023

\title{
Multiproduct Oligopoly and Trade Between Asymmetric Countries
}

\author{
Yi-Ling Cheng \\ Tunghai University and Academia Sinica \\ Takatoshi Tabuchi \\ The University of Tokyo
}

September 2016

CIRJE Discussion Papers can be downloaded without charge from:

http://www.cirje.e.u-tokyo.ac.jp/research/03research02dp.html

Discussion Papers are a series of manuscripts in their draft form. They are not intended for circulation or distribution except as indicated by the author. For that reason Discussion Papers may not be reproduced or distributed without the written consent of the author. 


\title{
Multiproduct Oligopoly and Trade Between Asymmetric Countries*
}

\author{
Yi-Ling Cheng ${ }^{\dagger} \quad$ Takatoshi Tabuchi ${ }^{\ddagger}$
}

September 29, 2016

\begin{abstract}
This paper develops a general equilibrium model of oligopolistic multiproduct firms conducting trade between asymmetric countries, in which heterogeneous firms entrants choose their product ranges and outputs. We show that there are fewer exporters in the larger country, and each produces a wider range of products but exports fewer varieties. We also show that while trade liberalization increases the total number of consumed varieties, it decreases the total number of firms and may reduce the product range of each firm. (JEL Classification: F12, L13)
\end{abstract}

Keywords: multiproduct firms, firm heterogeneity, cannibalization effect, product scope.

*We wish to thank Yasuhiro Sato and Jacques Thisse for valuable comments and suggestions.

†Tunghai University and Academia Sinica. No. 181, Section 2, Taichung Port Road, Taichung, 40704, Taiwan. E-mail: ylcheng@thu.edu.tw

${ }^{\ddagger}$ Faculty of Economics, University of Tokyo. Hongo-7-3-1, Bunkyo-ku, Tokyo 113-0033, Japan. E-mail: ttabuchi@e.u-tokyo.ac.jp (Corresponding author) 


\section{Introduction}

Multiproduct firms abound in the real world. Bernard et al. (2010) show that about 39 percent of U.S. manufacturing firms produce more than one product, and their production accounts for 87 percent of total sales. According to international trade data, the majority of export sales originate from multiproduct firms. Bernard et al. (2009) indicate that over 10 percent of exporters and 20 percent of importers trade more than 10 products and that the sales of these firms account for about 90 percent of the export and import value in 2000. In spite of their dominant presence, multiproduct firms have received little attention in the theory of international trade and economic geography. Few studies analyze the production, product scope and export of multiproduct firms, which are affected by globalization and trade liberalization.

General equilibrium models of international trade often confine themselves to singleproduct firms in the literature. The product scope of firms is generally not considered, and the product variety is assumed to be equal to the number of firms in the economy. In contrast, multiproduct firms are well studied in the field of industrial organization, for example, by Johnson and Myatt (2006) and Ottaviano and Thisse (2011). However, theses studies often focus on partial equilibrium, so that general equilibrium feedback through the interactions of different markets is neglected. Therefore, it is important to explore interactions across industries in a framework of multiproduct firms in the global economy.

Multiproduct firms also figure prominently in the recent literature on international trade (e.g., refer to Allanson and Montagna (2005), Bernard et al. (2011), Dhingra (2013), and Mayer et al. (2014)). These studies normally assume monopolistic competition between multiproduct firms, so that each firm has no market power. However, since multiproduct firms control nonnegligible sets of varieties, they behave like oligopolists (Ottaviano and Thisse, 2011). Accordingly, multiproduct firms should compete strategically in an oligopolistic market rather than a monopolistic competitive one.

In recent years, rapid globalization mergers and acquisitions have intensified oligopolistic competition in international markets. For instance, in the airline industry, the Air France-KLM merger in 2004 led to the buying of a $25 \%$ stake in Alitalia in 2008, while 
Lufthansa acquired stakes in the U.S.'s Jet-Blue and the U.K's Midland, and considered acquisitions in Brussels Airlines and Austrian Airlines. These developments were under close watch by big rival companies like American Airlines and Delta Air Lines. The music entertainment industry is another example of oligopoly. The global market is dominated by five international firms: Universal Music Group, Sony, Bertelsmann Music Group, Warner and EMI Group. There are many other oligopolistic firms in the film production and automobile industries.

Feenstra and Ma (2008), Baldwin and Gu (2009), and Eckel and Neary (2010) consider oligopolistic competition among multiproduct firms. However, Feenstra and Ma (2008) and Eckel and Neary (2010) confine themselves to a single globalized world without trade barriers, while Baldwin and $\mathrm{Gu}(2009)$ focus on symmetric countries.

In this paper, we develop a model of oligopolistic multiproduct firms conducting trade between countries of different sizes. The purpose is to clarify the role of strategic behaviors between multiproduct firms within the framework of new trade theory. In particular, we are interested in the impacts of trade liberalization on the product range of a multiproduct firm, the product diversification of an industry, and trade between countries of asymmetric sizes.

We consider multiproduct firms that are heterogeneous in their productivity in terms of marginal production cost. Firms make entry and exit decisions. Successful entrants choose their product ranges and outputs in oligopolistic competition. Unlike Melitz and Ottaviano (2008), we assume that heterogeneous entrants know their production costs when they decide whether to enter the market and that the productivity of potential entrants is uniformly distributed. This simplification enables us to obtain meaningful and analytical results and further insight.

Our main findings are summarized as follows. In an open economy with two asymmetric countries, we show that fewer exporters enter the larger country and produce fewer varieties for export to the foreign market although each of them offers a wider product range. Besides, the large country is a net importer, which shows the reverse home market effect. As trade costs fall, (i) the number of exporters increases but the total number of firms decreases, (ii) the product range and output of a non-exporter always decrease, whereas the product range and output of an exporter first increase and then decrease 
when the product demand is large, and (iii) the total number of varieties and outputs consumed always increase.

Some of our results contrast sharply with those in the literature on new trade theory which assumes single-product firms and/or monopolistic competition between multiproduct firms (see Melitz and Ottaviano, 2008; Bernard et al., 2011; Mayer et al., 2014). They consider behaviors of multiproduct firms conducting trade, but do not take the strategic effect into account. Furthermore, in order to examine how the market size affects the behaviors of multiproduct firms, we assume asymmetric country sizes with trade, whereas the literature such as Baldwin and Gu (2009) assumes symmetric countries.

The rest of this paper is organized as follows. Section 2 presents the model of oligopolistic multiproduct firms in a closed economy and characterizes the equilibrium. Section 3 extends the model to an open economy between two asymmetric countries and investigates the impacts of trade liberalization and country size on the number of firms, product scope, product diversification and industry outputs. Section 4 concludes.

\section{Closed Economy}

In this section, we first introduce a general equilibrium model of a closed economy and examine the entry and product scope of multiproduct oligopolists with heterogeneous productivity.

\subsection{Preferences and Demand}

Consider an economy with $L$ identical workers. The worker's preference is described by a quasi-linear utility function defined over a continuum of differentiated product varieties and a homogeneous good chosen as the numeraire:

$$
U=\alpha \sum_{i=1}^{m} \sum_{j=1}^{n_{i}} q_{i}^{c}(j)-\frac{\beta}{2} \sum_{i=1}^{m} \sum_{j=1}^{n_{i}}\left[q_{i}^{c}(j)\right]^{2}-\frac{\gamma}{2}\left[\sum_{i=1}^{m} \sum_{j=1}^{n_{i}} q_{i}^{c}(j)\right]^{2}+q_{0}^{c}
$$

where $q_{0}^{c}$ denotes the numeraire good and $q_{i}^{c}(j)$ is the individual consumption of variety $j \in$ $\left\{1, \ldots, n_{i}\right\}$ of the differentiated product produced by multiproduct firm $i \in\{1, \ldots, m\}$, where $n_{i}$ is the number of varieties produced by firm $i$, and $m$ is the number of firms in the economy. The total number of varieties of the differentiated product is given by 
$N=\sum_{i=1}^{m} n_{i}$. The parameters $\alpha, \beta$ and $\gamma$ are positive. A higher $\alpha$ means a stronger preference towards the differentiated varieties compared to the numeraire, a higher $\beta$ implies more bias toward love for variety, and a higher $\gamma$ means closer substitutes between varieties.

Assume that each worker supplies one unit of labor inelastically. The budget constraint of the worker can be written as:

$$
\sum_{i} \sum_{j} p_{i}(j) q_{i}^{c}(j)+q_{0}^{c}=w
$$

where $w$ is the wage and $p_{i}(j)$ is the price of variety $j$ produced by firm $i$. Solving (2) for the numeraire consumption, substituting the corresponding expression into (1), and solving the first-order conditions with respect to $q_{i}^{c}(j)$, we obtain the inverse demand of a worker for variety $j$ of firm $i$ :

$$
\begin{aligned}
p_{i}(j) & =\alpha-\beta q_{i}^{c}(j)-\gamma \sum_{i} \sum_{j} q_{i}^{c}(j) \\
& =\alpha-\beta \frac{q_{i}(j)}{L}-\gamma \frac{Q}{L}
\end{aligned}
$$

where $q_{i}(j) \equiv q_{i}^{c}(j) L$ and $Q \equiv \sum_{i} \sum_{j} q_{i}^{c}(j) L$ denote the market demand for the product $j$ of firm $i$, and the aggregate market demand over all varieties of all firms, respectively.

\subsection{Production and Profits}

There are a homogeneous good sector and a differentiated good sector. Production in both sectors requires labor, which is inelastically supplied by workers in a competitive market. The production technology of a homogeneous good is constant returns to scale with one unit of labor.

In the differentiated good sector, launching a variety requires $F$ units of labor as fixed overhead costs, and the subsequent production of each variety requires $c_{i}$ units of labor as marginal costs. Labor is freely mobile between the two sectors, so that the wage is equalized and is equal to one.

Multiproduct firms are heterogeneous in the marginal labor requirement, which is uniformly distributed over the interval of $[1, \infty)$ with density normalized to 1 , that is, $c_{i}=\{1,2, \ldots, \infty\}$. 
Each firm maximizes its profit given the inverse demand (3). Unlike Melitz (2003), each firm knows their production costs from the beginning and enters the market if its profit is positive. Let $c_{m}$ be the highest marginal cost of a firm that successfully enters the market so that the marginal costs of entrants are $c_{i}=1,2, \ldots, m$ with density equal to 1 and the number $m$ of entrants coincides with $c_{m}$.

Using (3), the profit of a firm with marginal cost $c_{i}$ is given by

$$
\begin{aligned}
\pi_{i} & =\sum_{j=1}^{n_{i}}\left[p_{i}(j)-c_{i}\right] q_{i}(j)-n_{i} F \\
& =\sum_{j}\left[\alpha-\beta \frac{q_{i}(j)}{L}-\gamma \frac{Q}{L}-c_{i}\right] q_{i}(j)-n_{i} F
\end{aligned}
$$

As firms are allowed to produce multiple products, the market should not be monopolistically competitive. The reason is as follows. Since there is a continuum of firms in monopolistic competition, each one is negligible in the sense that its action has no impact on the market (Ottaviano et al., 2002). Hence, when choosing its quantities and product scope, a firm accurately neglects the impact of its decision over the total output $Q$. That is, each firm considers $Q$ to be constant, and thus, the profit (4) becomes linear in $n_{i}$ implying the absence of the strategic and cannibalization effects. That is, introducing a new variety does not reduce sales of existing varieties.

However, each firm in oligopolistic competition is nonnegligible. In selecting its quantities and product scope, each firm takes the impact of its decision over $Q$ into account. That is, each firm considers that $Q$ is a function of its quantities and product scope. Owing to symmetry among the varieties $q_{i}(j)=q_{i}, Q$ is linear in $n_{i}$, and thus, the profit (4) is quadratic in $n_{i}$. The quadratic term $-\gamma\left(n_{i} q_{i}\right)^{2} / L$ is negative, which implies that the introduction of a new variety decreases revenues of existing varieties. Therefore, multiproduct firms must be in oligopolistic competition rather than monopolistic competition. This conclusion is valid for any standard utility function and for any strategic variables.

Following Ottaviano and Thisse (2011), each firm simultaneously chooses its product range and output of each variety. Because of oligopoly by multiproduct firms, they cannot neglect the change in the total output $Q=\sum_{i} \sum_{j} q_{i}(j)$ in their decisions of their product range $n_{i}$ and output $q_{i}(j)$ of each variety, $n_{i}$ and $q_{i}(j)$. That is, each firm takes changes 
in the first term of the following equation into account

$$
Q=Q_{i}+Q_{-i}=\sum_{j} q_{i}(j)+Q_{-i}
$$

where $Q_{i}$ denotes the output of firm $i$ and $Q_{-i}$ denotes the sum of the output by all competitors.

By substituting (5) into (4), differentiating it with respect to $q_{i}(j)$ and $n_{i}$, and using symmetry among varieties $q_{i}(j)=q_{i}$ for all $j=1,2, \ldots, n_{i}$, we obtain the equilibrium output for each variety and the product range of firm $i$ :

$$
\begin{aligned}
q & =q_{i}=\sqrt{\frac{F L}{\beta}} \\
n_{i} & =\frac{\sqrt{\beta}\left[L\left(\alpha-c_{i}\right)-\gamma Q-2 \sqrt{\beta F L}\right]}{\gamma \sqrt{F L}}
\end{aligned}
$$

Observe that the equilibrium output is constant for all firms in spite of the differences in the marginal $\operatorname{cost} c_{i}$, whereas the equilibrium product range decreases with the marginal cost. The demand parameters $\alpha, \beta$ and $\gamma$ and the marginal cost $c_{i}$ normally affect the equilibrium output in the case of single-product firms. However, they affect the product range rather than the output in the case of multiproduct firms, implying that the demand and production conditions are reflected by the decision regarding product scope rather than the quantity of the output.

\subsection{Free Entry Equilibrium}

Since firms with marginal cost lower than $m$ make positive profits and enter the market, the number of successful entrants, $m$, is determined by the free entry condition $\pi_{m}=0$. Since $Q=\sum_{i} n_{i} q_{i}$, plugging (6) and (7) into the profit (4) of a firm with marginal cost $c_{i}=m$, we have

$$
\pi_{m}=\frac{[2 A-m(1+m)]^{2} L}{4(1+m)^{2} \gamma}=0
$$

where $A \equiv \alpha-2 \sqrt{\beta F / L}$. Solving this for $m$, we immediately get the unique equilibrium number of multiproduct firms

$$
m=\frac{1}{2}(\sqrt{1+8 A}-1)
$$


For the market to be oligopolistic, we assume $m \geq 2$, which is equivalent to $A \geq 3$. This inequality suggests that the population size $L$ should be large enough and the fixed cost $F$ should be small enough. Otherwise, no firm enters the market.

We can also compute the equilibrium product scope of firm $i$ :

$$
n_{i}=\frac{\beta\left(\sqrt{1+8 A}-1-2 c_{i}\right)}{\gamma(\alpha-A)}
$$

which shows that more efficient firms with lower marginal costs $c_{i}$ produce more varieties. The equilibrium price of a variety

$$
p=p_{i}=\frac{1}{2}(\alpha+\sqrt{1+8 A}-1-A)
$$

is constant for all firms with different marginal costs. The total number of varieties is computed as

$$
N=\sum_{i} n_{i}=\frac{\beta(\sqrt{1+8 A}-1-2 A)}{\gamma(\alpha-A)}
$$

which is a measure of product diversification. The equilibrium total output is given by $Q=N q=N \sqrt{F L / \beta}$.

In a larger market with larger $L$, there are more successful entrants $m$ and each multiproduct firm provides more varieties $n_{i}$. The output $q$ of each variety is larger and the product price $p$ is lower. Thus, the product diversification $N$ and the total output $Q$ are also larger. These results coincide with those of Feenstra and Ma (2008) and Baldwin and $\mathrm{Gu}(2009)$.

Furthermore, we show that the average productivity of firms is lower in a larger market. This is because less efficient firms enter the larger market when, say, the fixed cost $F$ falls, and the number $m$ of firms increases.

This is in contrast to the findings of Feenstra and Ma (2008) and Baldwin and $\mathrm{Gu}$ (2009). For example, according to equations (24) and (25) in the study by Baldwin and $\mathrm{Gu}$ (2009), the average productivity is higher in a larger market. The difference is attributed to marginal cost information. While firms know their marginal production cost in our model, they have no information on the marginal cost before entering the market in their models. As a result, falling fixed cost induces inefficient firms to enter the market, which lowers the productivity in our model. However, it induces both efficient and inefficient firms to enter the market in their models. Therefore, although the cost cutoff is lower, 
the number of firms is larger in a larger market and thus the average productivity may be higher in their models.

\subsection{First-best and Second-best Optima}

There is a trade-off in multiproduct oligopoly under firm heterogeneity. If there are many firms, the competition gets intense, which raises consumers surplus and may increase social welfare. However, the existence of many firms implies the entry of less efficient firms, which increases the sum of the marginal costs of production. On the other hand, if there are few firms, they may exploit oligopolistic profits, which may distort the efficient allocation of resources. Nevertheless, since incumbent firms are efficient, the total production cost would be small.

It is obvious that the firm with the lowest marginal cost $c_{1}=1$ produces all varieties in the first-best optimum. However, since such a government-regulated monopoly is unrealistic in a market economy, we consider the second-best optimum, where the government policy is a tax or a subsidy. In what follows, we assume an ad valorem tax. ${ }^{1}$ The profit function (4) is rewritten as

$$
\pi_{i}=\sum_{j}\left[(1-t) p_{i}(j)-c_{i}\right] q_{i}(j)-n_{i} F
$$

where $t(<1)$ is the ad valorem tax rate. It is a tax if $t>0$ and subsidy if $t<0$.

Computing the first-order conditions and the free entry condition, we get the secondbest output of a variety, the second-best product scope per firm, and the second-best number of multiproduct firms:

$$
\begin{aligned}
q^{s} & =\sqrt{\frac{F L}{(1-t) \beta}} \\
n_{i}^{s} & =\frac{\beta\left[\sqrt{1+8(1-t) A}-\left(1+2 c_{i}\right)\right]}{(1-t) \gamma(\alpha-A)} \\
m^{s} & =\frac{1}{2}(\sqrt{1+8(1-t) A}-1)
\end{aligned}
$$

which are the same for all firms $i$. Comparing it with the equilibrium output $q$ given by (6), the equilibrium output $q$ is under supplied if a tax is levied $(0<t<1)$, whereas it is over supplied if a subsidy is given $(t<0)$.

\footnotetext{
${ }^{1}$ The results are qualitatively the same as in the case of quantity tax.
} 
We can also derive the second-best price and total number of varieties as

$$
\begin{aligned}
p^{s} & =\frac{(1-t)(\alpha-A)-1+\sqrt{1+8(1-t) A}}{2(1-t)} \\
N^{s} & =\frac{\beta[1+2(1-t) A-\sqrt{1+8(1-t) A}]}{(1-t) \gamma(\alpha-A)}
\end{aligned}
$$

The social welfare is defined by

$$
W \equiv \mathrm{CS}+\mathrm{PS}+\mathrm{TR}
$$

where the consumer surplus CS is the sum of all workers' utilities $L U$, the producer surplus PS is $\sum_{i=1}^{m} \pi_{i}$, and the tax revenue (or negative subsidy expense) TR is defined by

$$
\mathrm{TR}=\sum_{i} t n_{i}^{s} p^{s} q^{s}
$$

We want to maximize the social welfare $W$ with respect to the tax rate $t$. Although $W$ is a highly nonlinear function, we evaluate its derivative at $t=0$ for extreme values of $\alpha$.

When $\alpha$ is sufficiently large, we get

$$
\left.\lim _{\alpha \rightarrow \infty} \frac{\partial W}{\partial t}\right|_{t=0}=\infty
$$

Since the slope of $W$ is positive at $t=0$, there exists a positive tax rate $t_{s} \in(0,1)$. Comparing (6) and (8), we can say that the equilibrium output $q$ is too small. We can further say that the equilibrium number $m$ of firms is too large, and that the equilibrium number $N$ of varieties in the economy is too large. The intuition is that imposing a tax raises costs of firms, which damages less efficient firms. Their exit saves the high marginal costs as well as the fixed costs of each variety. Therefore, both the number of firms and the number of varieties decrease, whereas the output per firm increases. That is, in the presence of firm heterogeneity, the government should reduce the number of firms by imposing a tax. In the presence of the fixed cost per variety, the government should reduce the number of varieties by imposing a tax. ${ }^{2}$

However, the opposite occurs when $\alpha$ is small and approaches $2 \sqrt{\beta F / L}+3$, which corresponds to $A \rightarrow 3$. We have

$$
\left.\lim _{A \rightarrow 3} \frac{\partial W}{\partial t}\right|_{t=0}=-\frac{18 \beta F+37 \sqrt{\beta F L}+24 L}{60 \gamma}<0
$$

\footnotetext{
${ }^{2}$ Inducing low-productivity firms to exit the market would increase the profit/income differential. Therefore, there exists a trade-off between aggregate efficiency and equity.
} 
which means that the negative tax, that is, a subsidy, is more desirable than the no-tax equilibrium. Unlike the case of large $\alpha$, the equilibrium output is too large, the equilibrium number of firms is too small, and the equilibrium number of varieties in the economy is too small. That is, ad valorem subsidy encourages entry of firms and increases the number of varieties, which promotes competition among firms. In sum, we have the following.

Proposition 1 Oligopoly with a limited number efficient firms is desirable when the demand $\alpha$ is large, whereas further entry of firms is preferred when the demand is small.

\section{Open Economy}

In this section, we extend the multiproduct oligopoly model to an open economy having countries of different sizes in order to examine the home market effect and investigate the impact of trade costs. ${ }^{3}$ The two countries $r=1,2$ have population sizes of $L_{1}$ and $L_{2}$, respectively, where $L_{2}>L_{1}$. While the homogeneous good is freely traded, the differentiated good is traded with positive trade costs, where $\tau>1$ units of a good should be shipped in order for one unit to arrive at the destination. The other settings are the same as in the previous section.

In an open economy, firms decide whether to enter or not, select the quantity and product range. They also decide whether or not to export varieties to the foreign market. Thus, there are two kinds of firms, exporters and non-exporters. Exporters choose the quantity and product range for the domestic and foreign markets. We assume that they incur the additional fixed cost for each export variety so that the domestic varieties are different from export varieties. On the other hand, non-exporters choose the quantity and product range for the domestic market only.

In reality, companies often produce different versions/models of goods in order to cater to a variety of needs in different regions. For example, the cellphone Moto G is manufactured to include a U.S. model as well as an international model owing to the difference in operational frequencies. The U.S. model supports the frequency HSDPA $850 / 1700 / 1900 / 2100 \mathrm{MHz}$, which works appropriately with the capabilities of T-Mobile

\footnotetext{
${ }^{3}$ If two countries are of the same size, the analysis is straightforward, as done by Baldwin and Gu (2009).
} 
company, whereas the international model operates at HSDPA 850/900/2100 MHz. It is also common for book publishers to issue a local as well as an international edition in order to segment domestic and foreign markets.

Because domestic and export varieties are different, the domestic and foreign markets are segmented. The profits of export firm $i$ located in country $r$ are to be separated into the domestic and export profits as

$$
\begin{aligned}
\pi_{r r}(i) & =\sum_{j=1}^{n_{r r}(i)}\left[p_{r r}(i, j)-c_{i}\right] q_{r r}(i, j)-n_{r r}(i) F \\
\pi_{r s}(i) & =\sum_{j=1}^{n_{r s}(i)}\left[p_{r s}(i, j)-\tau c_{i}\right] q_{r s}(i, j)-n_{r s}(i) F
\end{aligned}
$$

where $\pi_{r r}(i)$ denotes the profit of domestic varieties $j$ of firm $i$ located in country $r$ and $\pi_{r s}(i)$ is the profit of varieties exporting to foreign country $s$. Notations $n_{r r}(i)$ and $n_{r s}(i)$ are the numbers of varieties produced by firm $i$ in country $r$ for the domestic and foreign markets, respectively; $p_{r r}(i, j)$ and $p_{r s}(i, j)$ are the corresponding prices of variety $j$; and $q_{r r}(i, j)$ and $q_{r s}(i, j)$ are the corresponding outputs of variety $j$.

An exporter $i$ in country $r$ maximizes the profit $\pi_{r r}(i)$ with respect to $n_{r r}(i)$ and $q_{r r}(i, j)$ as well as the profit $\pi_{r s}(i)$ with respect to $n_{r s}(i)$ and $q_{r s}(i, j)$, while a non-exporter in $r$ chooses $n_{r r}(i)$ and $q_{r r}(i, j)$ to maximize the profit $\pi_{r r}(i)$ only. Each country has three types of firms: domestic non-exporters, domestic exporters and foreign exporters. All these firms compete in the same oligopolistic market.

Since the behaviors of the first two types of firms in the domestic market are the same, there are two first-order conditions $\partial \pi_{r r}(i) / \partial q_{r r}(i, j)=\partial \pi_{r r}(i) / \partial n_{r r}(i)=0$. For the foreign exporters, there are two first-order conditions $\partial \pi_{s r}(i) / \partial q_{s r}(i, j)=\partial \pi_{s r}(i) / \partial n_{s r}(i)=$ 0 . Because of the symmetry among varieties of a firm, we have $q_{r r}(i, j)=q_{r r}(i)$ and $q_{s r}(i, j)=q_{s r}(i)$ for all $j=1,2, \ldots, n_{i}$, and thus, we obtain the equilibrium outputs of a domestic variety and an exporting variety

$$
\begin{aligned}
& q_{r r}=q_{r r}(i)=\sqrt{\frac{F L_{r}}{\beta}} \\
& q_{r s}=q_{r s}(i)=\sqrt{\frac{F L_{s}}{\beta}}
\end{aligned}
$$

and the product ranges of the domestic and foreign markets, which involve $Q_{r}$ and $Q_{s}$ to be determined by free entry conditions. Similarly, the prices of domestic and export 
varieties can be computed. The equilibrium outputs are invariant with respect to $c_{i}$ and $\tau$, implying that they are the same for all firms with different marginal costs between domestic and import firms.

\subsection{Free Entry Equilibrium}

Because there are two kinds of firms, there are two cutoff points $m_{r s}$ and $m_{r r}$ in country $r$. The marginal cost of exporters is $c_{i}=1,2, \ldots, m_{r s}$ and that of non-exporters is $c_{i}=m_{r s}+1, m_{r s}+2, \ldots, m_{r r}$. The number of exporters and non-exporters in country $r$ is given by $m_{r s}$ and $m_{r r}-m_{r s}$, respectively. They are determined by the free-entry conditions as shown below.

The total output in country $r$ can be written as

$$
\begin{aligned}
Q_{r} & =\sum_{i=1}^{m_{r r}} n_{r r}(i) q_{r r}(i)+\sum_{i=1}^{m_{s r}} n_{r s}(i) q_{r s}(i) \\
& =\frac{2 A_{r}\left(m_{r r}+m_{s r}\right)-m_{r r}\left(1+m_{r r}\right)-\tau m_{s r}\left(1+m_{s r}\right)}{2 \gamma\left(1+m_{r r}+m_{s r}\right)} L_{r}
\end{aligned}
$$

where $A_{r} \equiv \alpha-2 \sqrt{\beta F / L_{r}}$. Substituting the equilibrium number of varieties, outputs, and prices into the domestic profit of a firm with $m_{r r}$ and the export profit of a firm with $m_{r s}$, we have the following free-entry conditions:

$$
\begin{aligned}
& \pi_{r r}\left(m_{r r}\right)=\frac{\left[\tau m_{s r}\left(1+m_{s r}\right)-m_{r r}\left(1+m_{r r}+2 m_{s r}\right)+2 A_{r}\right]^{2} L_{r}}{4 \gamma\left(1+m_{r r}+m_{s r}\right)^{2}}=0 \\
& \pi_{r s}\left(m_{r s}\right)=\frac{\left[m_{s s}\left(1+m_{s s}\right)-\tau m_{r s}\left(1+m_{r s}+2 m_{s s}\right)+2 A_{s}\right]^{2} L_{s}}{4 \gamma\left(1+m_{s s}+m_{r s}\right)^{2}}=0
\end{aligned}
$$

Then, the total number of firms and the number of exporters in country $r$ are uniquely determined as

$$
m_{r r}=\frac{\tau \sqrt{2 A_{r}}}{\sqrt{\tau(1+\tau)}}, \quad m_{r s}=\frac{\sqrt{2 A_{s}}}{\sqrt{\tau(1+\tau)}}
$$

which indicates $m_{r r} / m_{r s}=\tau>1$. In order for trade to occur, there exists at least one exporter $m_{r s} \geq 1$, so that we must have

$$
A_{2} \geq A_{1} \geq \frac{\tau(1+\tau)}{2}
$$

Examining (11), we immediately obtain the following. 
Proposition 2 Consider two asymmetric countries with trade costs.

(i) There are more firms $m_{22}>m_{11}$ but fewer exporters $m_{21}<m_{12}$ in the larger country.

(ii) As the trade costs fall, the number $m_{r s}$ of exporters increases while the total number $m_{r r}$ of firms decreases.

According to first statement of this proposition, the domestic market is larger whereas the foreign market is smaller in the larger country. Therefore, more non-exporters and fewer exporters exist in the larger country. The former implies that the productivity differential of firms is wider in the larger country because less efficient firms enter the larger domestic market. However, the opposite is true in the latter case. As a result, the average productivity of exporters and non-exporters is higher and lower, respectively, in the larger country.

In the second statement, falling trade costs induce more exporters to enter and more non-exporters to exit because of intensified competition with foreign firms. As we show later, the prices decrease with the trade costs, reducing the domestic profit $\pi_{r r}(9)$, and thus, some firms exit. This means that the exit of non-exporters dominates entry of exporters.

Next, we obtain the number of varieties supplied by a non-exporter (which is also equal to the number of domestic varieties provided by an exporter) and the number of export varieties supplied by an exporter:

$$
n_{r r}(i)=\frac{2 \beta\left(\sqrt{\frac{2 \tau A_{r}}{1+\tau}}-c_{i}\right)}{\gamma\left(\alpha-A_{r}\right)}, \quad n_{r s}(i)=\frac{2 \beta\left(\sqrt{\frac{2 \tau A_{s}}{1+\tau}}-\tau c_{i}\right)}{\gamma\left(\alpha-A_{s}\right)}
$$

As in the closed economy, we observe that the equilibrium product range decreases with the marginal cost. While the product range of a non-exporter $i$ in country $r$ is $n_{r r}(i)$, the product range of an exporter in country $r$ is $n_{r r}(i)+n_{r s}(i)$. From (12) and $\tau>1$, $n_{r s}(i)<n_{r r}(i)$ always holds. Because $n_{r r}(i)$ and $n_{r s}(i)$ are decreasing in $c_{i}$, more efficient firms provide more varieties in the domestic and foreign markets. Furthermore, $n_{r r}(i)$ is increasing in $L_{r}$, which implies $n_{22}(i)>n_{11}(i)$ for all $L_{2}>L_{1}$. Similarly, $n_{r s}(i)$ is increasing in $L_{s}$, which implies $n_{21}(i)<n_{12}(i)$ when $L_{2}>L_{1}$. Thus, given the same marginal cost, each firm produces more varieties for the domestic market $n_{22}(i)>n_{11}(i)$ 
and exports fewer varieties $n_{21}(i)<n_{12}(i)$ in the larger country. This is understood by the fact that the larger country has a larger domestic market and a smaller foreign market.

Furthermore, the following can be shown.

Proposition 3 The product ranges of a non-exporter and an exporter are wider in the larger country: $n_{22}(i)>n_{11}(i)$ and $n_{22}(i)+n_{21}(i)>n_{11}(i)+n_{12}(i)$.

Because the varieties are symmetric, the price and quantity of each variety are the same within a country. Therefore, firm $i$ in the larger country strategically increases the number of domestic varieties in order to secure profits in the larger market, which is reminiscent of market preemption. Such a brand proliferating strategy can be used by multiproduct, but not single-product firms.

On the other hand, firm $i$ in the larger country does not export much because the foreign market is small. The difference in domestic varieties is much larger than that in export varieties because of the existence of trade costs, and thus, the product range of a firm is wider in the larger country: $n_{22}(i)+n_{21}(i)>n_{11}(i)+n_{12}(i)$. Combining Propositions 3 and 2(i), we can say that although there are fewer exporters in the larger country, each firm produces a wider range of products.

The equilibrium prices are obtained as

$$
\begin{aligned}
& p_{r r}=p_{s r}=\frac{\alpha-A_{r}}{2}+\sqrt{\frac{2 \tau A_{r}}{1+\tau}} \\
& p_{r s}=p_{s s}=\frac{\alpha-A_{s}}{2}+\sqrt{\frac{2 \tau A_{s}}{1+\tau}}
\end{aligned}
$$

which are common for all $i$ as in the closed economy. Then, we can readily show that the price is lower in the larger country: $p_{12}=p_{22}<p_{11}=p_{21}$ owing to keen competition in the larger market. Obviously, all the prices decrease as trade costs fall.

We compute the number of domestically produced varieties and the number of varieties imported into country $r$ :

$$
\begin{aligned}
& N_{r r}=\sum_{i=1}^{m_{r r}} n_{r r}(i)=\frac{2 \beta}{\gamma\left(\alpha-A_{r}\right)}\left[\frac{\tau A_{r}}{1+\tau}-\sqrt{\frac{\tau A_{r}}{2(1+\tau)}}\right] \\
& N_{s r}=\sum_{i=1}^{m_{s r}} n_{s r}(i)=\frac{2 \beta}{\gamma\left(\alpha-A_{r}\right)}\left[\frac{A_{r}}{1+\tau}-\sqrt{\frac{\tau A_{r}}{2(1+\tau)}}\right]
\end{aligned}
$$


Accordingly, the total number of varieties consumed in country $r$ are given by $N_{r}^{C}=$ $N_{r r}+N_{s r}$. Next, we may calculate the output of domestically produced varieties as $Q_{r r}=N_{r r} q_{r r}$, and the output exported from countries $r$ to $s$ as $Q_{s r}=N_{s r} q_{s r}$. Therefore, the total output available in country $r$ is $Q_{r}^{C}=Q_{r r}+Q_{s r}$.

Based on the foregoing, we establish the following results in an open economy of two asymmetric countries conducting trade for a given marginal cost.

Proposition 4 The reverse home market effect holds: $p_{21} Q_{21}<p_{12} Q_{12}$.

The proof is in Appendix 1. The results in Propositions 3, 2(ii) and (10) together imply that the larger country exports fewer varieties $N_{21}<N_{12}$ and has a smaller export volume $Q_{21}<Q_{12}$; moreover, each worker in the larger country enjoys more varieties $N_{2}^{C}>N_{1}^{C}$ and consumes more volume $Q_{2}^{C} / L_{2}>Q_{1}^{C} / L_{1}$. Since the price is lower in the larger country, the utility therein must be higher.

Proposition 4 appears consistent with the fact that a large country such as the U.S. has been experiencing net import. According to the bilateral trade data (OECD.Stat) between the U.S. and Canada for 1990-2015 (excluding agricultural products), the export from the U.S. to Canada $p_{21} Q_{21}$ is always less than Canadian export to the U.S. $p_{12} Q_{12}$. More generally, the correlation between the net export and GDP is -0.20 , which is significantly negative at the 0.01 level as per the bilateral trade data of the OECD countries in 2010. This result is contrary to the definition of the home market effect: a country whose share of demand for a good is larger than average will be a net exporter of that good (Crozet and Trionfetti, 2008).

The reverse home market effect in Proposition 4 may be attributed to the assumption that domestic and exporting markets are segmented, where firms make a separate decision between domestic and foreign markets. Because firms in the smaller country face larger foreign demand, they provide more export varieties than those in the larger country. On the other hand, if the markets are not segmented, the home market effect would hold. This is because firms provide the same number of varieties to both countries without market segmentation and because access to the larger market is worse for firms in the smaller country. Another reason for the reverse home market effect may be the assumption of the identical density of firm productivity between asymmetric countries. If there are more 
efficient firms in the larger country, then more outputs are produced, so that the home market effect is also possible. ${ }^{4}$

Next, we examine the effect of falling trade costs on the number of varieties.

Proposition 5 Assume that the trade costs steadily fall.

(i) For a given marginal cost, the product range $n_{r r}(i)$ of non-exporters always decreases. The product range $n_{r r}(i)+n_{r s}(i)$ of exporters is inverted $U$-shaped for large demand $\alpha$ while it always increases for small demand $\alpha$.

(ii) The total number $N_{r}^{C}=N_{r r}+N_{s r}$ of consumed varieties always increases.

The proof appears in Appendix 2. Trade liberalization seems to promote an increase in the product scope of each firm because of better access to the foreign market. However, this is often counterproductive because it intensifies the oligopolistic competition due to the entry of exporters as shown in Proposition 2(ii). According to Proposition 5(i), falling trade costs decrease the product ranges of both non-exporters and exporters when market demand is large and trade costs are small. ${ }^{5}$ This product scope shrinking effect is consistent with that of Baldwin and Gu (2009), wherein Figure 15.3 shows that the number of products per Canadian plant has been decreasing over time for non-exporters and exporters especially when NAFTA was concluded. Table I of Bernard et al. (2011) also shows that trade liberalization induces Canadian firms to reduce the range of products.

On the other hand, when trade costs are large, falling trade costs increase the product ranges of exporters. Furthermore, Proposition 5(ii) states that the total number of consumed varieties always increases as trade costs fall. This product scope expansion effect is in agreement with the empirical findings reported in Table 1 of Feenstra (1994) and Table 1 of Broda and Weinstein (2006), who show increasing trends in the number of imported varieties. This is because falling trade costs induces non-exporters to become productive exporters.

\footnotetext{
${ }^{4}$ According to our numerical analysis, the home market effect is likely to hold by relaxing one of the two assumptions.

${ }^{5}$ This is because trade liberalization promotes entry of exporters for larger demand and lower trade costs, which is confirmed by $m_{r s}$ in (11). Further entry intensifies oligopolistic competition, which decreases the product range of each firm.
} 
The aforementioned two results appear to contradict each other. However, the underlying intuition is straightforward. As trade costs fall, the product range for each firm shrinks as per Proposition 5(i) owing to keener competition, but non-exporters near the cutoff point (threshold $m_{r s}$ ) become exporters as per Proposition 2. Because the product range $n_{r r}+n_{r s}$ of exporters is much wider than that $n_{r r}$ of non-exporters, the product scope shrinking effect is dominated by the product scope expansion effect, so that the total number of consumed varieties eventually increases.

In Appendix 3, we show that falling trade costs have a positive impact on the welfare of workers in both countries, which is intuitive. However, falling trade costs widens the welfare disparity between the countries. That is, the welfare of the larger country increases at a faster speed compared to that of the smaller one. Hence, trade liberalization is beneficial to each country although this is not desirable from the viewpoint of international equality. The widening of welfare disparity is attributed to the assumption of market segmentation between domestic and foreign countries. Even if the trade costs approach zero, prices differ between the countries because of market segmentation. ${ }^{6}$

\section{Conclusion}

We have investigated strategic behavior of multiproduct oligopolists. In a closed economy, we showed that reduction in the fixed cost increases the number of firms and the number of varieties supplied by each firm, but decreases the output of each variety and its price. We also showed that it is socially desirable to limit the number of firms in the case of a large market, whereas increased entry of firms is preferred for a small market.

We then examined an open economy with two asymmetric countries. We showed that while the larger country has more firms producing more varieties for the domestic market, fewer exporters produce fewer varieties for the foreign market. We also observed that an expanded product scope, and higher total consumption and welfare in the larger country.

Trade liberalization promotes international trade, but intensifies oligopolistic competition. We have shown that the number of exporters increases, whereas the total number

\footnotetext{
${ }^{6}$ If the markets are not segmented, we can arrive at the opposite result numerically; the welfare disparity decreases as trade costs fall.
} 
of firms decreases. The product range and output of a non-exporter always decrease, whereas the product range and output of an exporter first increase and then decrease due to the interplay between the product scope shrinking effect and the product scope expansion effect. The numbers of exported varieties and exported volumes increase in both countries.

\section{Appendix 1: Proof of Proposition 4}

While $p_{12} Q_{12}$ is a function of $L_{2}, p_{21} Q_{21}$ is a function of $L_{1}$ and they are equal if $L_{1}=L_{2}$. Therefore, it is sufficient to show that

$$
\frac{\partial\left(p_{12} Q_{12}\right)}{\partial A_{2}}=\frac{\beta F}{2 \gamma \sqrt{A_{2}}\left(\alpha-A_{2}\right)^{3}(\tau+1)^{3 / 2}} g>0
$$

where

$$
\begin{aligned}
g & \equiv\left[4 \sqrt{(\tau+1) A_{2}}-\sqrt{2 \tau}(\tau+1)\right] \alpha^{2}-4\left[\sqrt{(\tau+1) A_{2}^{3}}-3 \sqrt{2 \tau} A_{2}+2 \tau \sqrt{(\tau+1) A_{2}}\right] \alpha \\
& +\sqrt{2 \tau}(\tau+5) A_{2}^{2}-8 \tau \sqrt{(\tau+1) A_{2}^{3}}
\end{aligned}
$$

Because $A_{2}=\alpha-2 \sqrt{\beta F / L_{2}}>(\tau+1) \tau / 2$, the coefficient of $\alpha^{2}$ in $g$ is positive. That is, $\partial g / \partial \alpha$ is increasing in $\alpha$ while $\alpha$ is larger than $A_{2}$. Then,

$$
\frac{\partial g}{\partial \alpha}>\left.\frac{\partial g}{\partial \alpha}\right|_{\alpha=A_{2}}=\frac{2 h}{\sqrt{A_{2}}}
$$

where

$$
h \equiv 2 \sqrt{\tau+1} A_{2}-(\tau-5) \sqrt{2 \tau A_{2}}-4 \tau \sqrt{\tau+1}
$$

Since $h$ is shown to be positive by using $A_{2}>(\tau+1) \tau / 2, g$ is increasing in $\alpha$. We thus have

$$
g>\left.g\right|_{\alpha=A_{2}}=16 \sqrt{2 \tau A_{2}^{3}}\left[\sqrt{A_{2}}-\sqrt{(\tau+1) \tau / 2}\right]>0
$$

Because $\partial A_{2} / \partial L_{2}>0$, it is shown that $\frac{\partial\left(p_{12} Q_{12}\right)}{\partial L_{2}}>0$. 


\section{Appendix 2: Proof of Proposition 5}

(i) Differentiation with $\tau$ yields

$$
\begin{aligned}
& \frac{\partial n_{r r}(i)}{\partial \tau}=\frac{\beta \sqrt{2 A_{r}}}{\gamma\left(\alpha-A_{r}\right) \sqrt{\tau}\left[(1+\tau) L_{r}\right]^{3 / 2}}>0 \\
& \frac{\partial\left(n_{r r}(i)+n_{r s}(i)\right)}{\partial \tau}=\frac{2 \sqrt{2} \beta c_{i}\left(\alpha-A_{s}\right)\left[B-\sqrt{\tau}(1+\tau)^{3 / 2}\right]}{\gamma \sqrt{2 \tau}(1+\tau)^{3 / 2}\left(\alpha-A_{r}\right)\left(\alpha-A_{s}\right)} \gtreqless 0 \quad \text { if } B \gtreqless \sqrt{\tau}(1+\tau)^{3 / 2}
\end{aligned}
$$

where $\alpha$ is large enough to satisfy

$$
B \equiv \frac{\left(\alpha-A_{r}\right) \sqrt{A_{s}}+\left(\alpha-A_{s}\right) \sqrt{A_{r}}}{\sqrt{2} c_{i}\left(\alpha-A_{s}\right)}>2^{3 / 2} .
$$

This inequality ensures that $\frac{\partial\left(n_{r r}(i)+n_{r s}(i)\right)}{\partial \tau}>0$ for small $\tau$, while $\frac{\partial\left(n_{r r}(i)+n_{r s}(i)\right)}{\partial \tau}<0$ for large $\tau$. That is, when trade costs steadily decrease, $n_{r r}(i)+n_{r s}(i)$ first increases and then decreases.

(ii) Differentiating $N_{r}^{C}$ with respect to $\tau$, we immediately get $\partial N_{r}^{C} / \partial \tau<0$.

\section{Appendix 3: Proof about the welfare}

(i) The welfare of workers in country $r$ can be written as

$$
U_{r}=\left(\alpha-p_{r r}-\frac{\beta+\gamma N_{r}^{C}}{2 L_{r}} q_{r r}\right) \frac{N_{r}^{C}}{L_{r}} q_{r r}+w
$$

which is a function of $q_{r r}, p_{r r}$ and $N_{r}^{C}$. We know that $q_{r r}$ is constant with respect $\tau, p_{r r}$ is increasing in $\tau$, and $N_{r}^{C}$ is decreasing in $\tau$. First, we can readily show that $\partial U_{r} / \partial p_{r r}<0$, and thus $\left(\partial U_{r} / \partial p_{r r}\right)\left(\partial p_{r r} / \partial \tau\right)<0$. Second, substituting $q_{r r}, p_{r r}$ and $N_{r}^{C}$ into the partial derivative of $U_{r}$ with respect to $N_{r}^{C}$, we get $\partial U_{r} / \partial N_{r}^{C}=F / L>0$, and thus $\left(\partial U_{r} / \partial N_{r}^{C}\right)\left(\partial N_{r}^{C} / \partial \tau\right)<0$. Hence, $\partial U_{r} / \partial \tau<0$.

(ii) In addition, we have $p_{22}<p_{11}$ for $L_{2}>L_{1}$. We can easily show that $0<$ $\partial p_{11} / \partial \tau<\partial p_{22} / \partial \tau$. Thus, falling trade costs widens the price differential. Similarly, we get $N_{2}^{C}>N_{1}^{C}$ for $L_{2}>L_{1}$ and we can also show that $\partial N_{2}^{C} / \partial \tau<\partial N_{1}^{C} / \partial \tau<0$. Thus, falling trade costs widens the variety differential. Putting the two results together with $\partial U_{r} / \partial p_{r r}<0$ and $\partial U_{r} / \partial N_{r}^{C}>0$, we have that $\partial U_{2} / \partial \tau<\partial U_{1} / \partial \tau<0$. 


\section{References}

[1] Allanson, P. and Montagna, C. (2005) Multiproduct firms and market structure: An explorative application to the product life cycle, International Journal of Industrial Organization 23(7-8), 587-597.

[2] Baldwin, J. and Gu, W. (2009) The impact of trade on plant scale, production-run length and diversification, in Dunne, T., Jensen, J. B. and Roberts, M. J. (eds.), Producer Dynamics: New Evidence from Micro Data, University of Chicago Press, Chicago.

[3] Bernard, A. B., Jensen, J. B. and Schott, P. K. (2009), Importer, exporter, and multinationals: A portrait of firms in the U.S. that trade goods, in Dunne, T., Jensen, J. B. and Roberts, M. J., (eds.), Producer Dynamics: New Evidence from Micro Data, University of Chicago Press, Chicago.

[4] Bernard, A. B., Redding, S. J. and Schott, P. K. (2010) Multiple-product firms and product switching, American Economic Review 100(1), 70-97.

[5] Bernard, A. B., Redding, S. J. and Schott, P. K. (2011) Multi-product firms and trade liberalization, Quarterly Journal of Economics 126(3), 1271-1318.

[6] Broda, C., and Weinstein, D. (2006) Globalization and the gains from variety, The Quarterly Journal of Economics 121(2), 541-585.

[7] Crozet, M. and Trionfetti, F. (2008) Trade costs and the home market effect, Journal of International Economics 76(2), 309-321.

[8] Dhingra, S. (2013) Trading away wide brands for cheap brands, American Economic Review 103(6), 2554-84.

[9] Eckel, C. and Neary, J. P. (2010) Multi-product firms and flexible manufacturing in the global economy, Review of Economic Studies 77(1), 188-217.

[10] Feenstra, R. (1994) New product varieties and the measurement of international prices, American Economic Review 84(1), 157-177. 
[11] Feenstra, R. C. and Ma, H. (2008) Optimal choice of product scope for multiproduct firms under monopolistic competition, in Helpman, E., Marin, D. and Verdier, T. (eds.), The Organization of Firms in a Global Economy, Harvard University Press, Cambridge MA.

[12] Johnson, J. P. and Myatt, D. P. (2006) Multiproduct Cournot oligopoly, Rand Journal of Economics 37(3), 583-601.

[13] Mayer, T., Melitz, M. J. and Ottaviano, G. I. P. (2014) Market size, competition, and the product mix of exporters, American Economic Review 104(2), 495-536.

[14] Melitz, M. J. (2003) The impact of trade on intra-industry reallocations and aggregate industry productivity, Econometrica 71(6), 1695-725.

[15] Melitz, M. J. and Ottaviano G. I. P. (2008) Market size, trade, and productivity, Review of Economic Studies 75(1), 295-316.

[16] Ottaviano, G. I. P., Tabuchi, T. and Thisse, J.-F. (2002) Agglomeration and trade revisited, International Economic Review 43(2), 409-436.

[17] Ottaviano, G. I. P. and Thisse, J.-F. (2011) Monopolistic competition, multiproduct firms and product diversity, The Manchester School 79(5), 938-951. 